\title{
EDUCAÇÃO E DIVERSIDADE: AS EXPERIÊNCIAS EXITOSAS QUE RECONHECEM OS SABERES E FAZERES DA CULTURA NA ESCOLA
}

\author{
Neide da Silva CAMPOS ${ }^{1}$ \\ Beleni Saléte GRANDO ${ }^{2}$ \\ Luiz Augusto PASSOS ${ }^{3}$
}

RESUMO: Pesquisamos as culturas populares em interface com a educação escolar para compreender as relações de poder instituída nas práticas educativas que impedem uma práxis voltada ao reconhecimento da diversidade étnico-cultural. Delimitamos experiências exitosas em dois municípios cuja constituição populacional resulta de conflitantes processos de colonização em Mato Grosso. Pautados em pesquisas anteriores nas quais identificamos as outras dinâmicas de poder entre gerações que alimentam a vida coletiva com uma educação marcada no corpo que se sabe, que reza, dança, come e brinca nas festas de santo. Concluímos que o professor não consegue transpor as barreiras do sistema escolar diante de uma realidade inacabada, complexa e dialética, sem uma formação pautada na compreensão da realidade social diversificada e do aprender coletivo.

PALAVRAS-CHAVE: Formação de professores. Culturas populares. Experiência exitosas.

\section{INTRODUÇÃO}

Neste texto, buscamos discutir as experiências exitosas com ênfase na cultura popular para a educação da criança e do jovem na escola, tendo por referência suas aprendizagens nas festas da cultura popular e reconhecendo nestes saberes e práticas aprendidos no contexto familiar e comunitário; conhecimentos relevantes para a educação intercultural e o sucesso do aluno no processo de educação escolar. A pesquisa buscou identificar nas escolas públicas de Cáceres e Nova Olímpia, em Mato Grosso, duas realidades diferentes em termos de processos históricos de constituição de

\footnotetext{
${ }^{1}$ Mestre em Educação. UFMT - Universidade Federal de Mato Grosso. Pesquisadora do Grupo de Pesquisa sobre Corpo, Educação e Cultura - COEDUC e do Grupo de Pesquisa em Movimentos Sociais e Educação- GPMSE. UFMT - Universidade Federal do Mato Grosso. Cuiabá - MT - Brasil. 78025-280 neidinhacampos@gmail.com.

2 Pós-doutora em Antropologia Social. Professora. UFMT - Universidade Federal de Mato Grosso. Coordenadora do COEDUC - Grupo de Pesquisa sobre Corpo, Educação e Cultura. UFMT Universidade Federal do Mato Grosso. Cuiabá - MT - Brasil. 78060-900 - beleni.grando@ gmail.com.

${ }^{3}$ Doutor em Educação Pública. UFMT - Universidade Federal de Mato Grosso. Doutor em Educação. PUC - Pontifícia Universidade Católica de São Paulo. Professor adjunto e Coordenador do Grupo de Pesquisa em Movimentos Sociais e Educação- GPMSE. UFMT - Universidade Federal do Mato Grosso. Cuiabá - MT - Brasil. 78060-900 - passospassos@gmail.com.
} 
sua população, ambas marcadas por conflitos interétnicos nos quais se pautam preconceitos reproduzidos no cotidiano da escola, evidenciando de forma pejorativa as identidades, os saberes e os fazeres dos alunos e alunas e seus familiares que compõe a comunidade escolar.

Definimos como espaço de investigação, após diagnóstico inicial pautado em pesquisas anteriores desenvolvidas em Cáceres-MT, as escolas cujas experiências tiveram êxito e eram reconhecidas pelos pares, como práticas educativas que incluíam a cultura popular no currículo. Delimitamos na pesquisa as práticas pedagógicas cujo conteúdo pautava-se na cultura da comunidade escolar, aqui identificada como cultura popular, ou seja, a cultura que identifica a população majoritária no município e expressa sua realidade sociocultural.

Estas práticas pedagógicas, cujo êxito é reconhecido pela comunidade escolar e pelas professoras que as desenvolveram, são as experiências exitosas nas quais nos pautamos para compreender as implicações da formação dos professores/professoras no desenvolvimento de práticas educativas que reconhecem os saberes e fazeres do aluno e aluna para implementar novos saberes e fazeres de responsabilidade da educação escolar.

Compreenderemos como experiências exitosas aquelas que, a nossos olhos, ressaltarem e vivenciarem a cultura da solidariedade, a dimensão festiva, o reconhecimento do outro e o gosto sentido da identidade evocada nesses eventos. Compreenderemos por exitosas aquelas que enaltecem a vida e produzem mais vida, mais compaixão, mais responsabilidade com o mundo e com os outros, portanto que humanizem, educando a todos os que delas participam.

Consideramos exitosas aquelas que, antes de tudo, têm o compromisso sólido com o conhecimento formal, mas que não negam as diversidades e as possibilidades de engendrar por outros caminhos. É na direção desses diferentes caminhos que os educadores e as educadoras procuram seguir.

É uma educação dialógica, em que o educando é incitado a dizer a sua palavra, de onde veio, qual a sua cultura e identidade. Uma educação que valoriza as diversidades culturais e vá para além dela. Uma experiência em que a sala de aula é apenas mais uma possibilidade de educação, que ler e escrever não se limitem ao fazer o dever de casa, mas que sirvam para a busca e o encontro das autonomias. Uma experiência exitosa é isso, é tudo que produz sentidos tanto para o educador quanto para o educando. 
Tomamos como referência as experiências educativas com a cultura popular em duas cidades de Mato Grosso, Cáceres, uma cidade que nasceu como vilarejo em 1778, que faz fronteira pantaneira com a Bolívia, cuja história se mistura à colonização portuguesa e os avanços das fronteiras em busca de ouro, com a exploração da mão de obra escrava de indígenas e negros; e Nova Olímpia-MT, uma cidade que inicia um processo de constituição como distrito de Barra do Bugres-MT (local tradicional de passagem da Comitiva de Rondon no qual se instalou o Posto Indígena Umutina) em 1960, para somente em 1970 iniciar um processo de povoado, fortalecido com a chegada de trabalhadores oriundos da Bahia, Alagoas e Ceara, além dos de São Paulo.

Inicialmente os dois municípios são ligados ao processo de exploração extrativista da poaia, cuja riqueza da planta nativa com valor medicinal e econômico relacionado à sua exportação para Alemanha, pois sendo espaço ocupado por populações nativas, estes são usados como os melhores trabalhadores que circulam e dominam o território banhado pelo Rio Paraguai. No entanto, os mesmos vão se diferenciar em termos de composição populacional, especialmente após a década de oitenta, com novas frentes de "ocupação" da região de Barra do Bugres, que vai se constituir como espaço de grandes latifúndios que passam a explorar a terra com a plantação de borracha e posteriormente de cana-de-açúcar, demandando grande contingente de trabalhadores oriundos especialmente do Nordeste. Estes, sem condições objetivas de retornar aos seus municípios de origem, passam a demandar uma estrutura de apoio para o pós-colheita, uma nova cidade.

Temos assim, em Cáceres ${ }^{4}$, uma cidade que vive as tradições da cultura matogrossense pantaneira, cujas festas de santo são resultantes da dinâmica da cultura e religiosidade do período colonial, e Nova Olímpia ${ }^{5}$, que embora tenha uma população predominante do Nordeste, cujo símbolo religioso e monumento que a marca é a imagem de Padre Cícero, convive com a população nativa e também tem como marca cultural de origem a vinculação às tradições populares das festas de santo.

\footnotetext{
4 Os dados populacionais disponíveis no sitio oficial são de 2008 , cuja população era de 86.805 habitantes, tendo como área 24.398,399 km², com uma densidade de 3,55 hab. $/ \mathrm{km}^{2}$. Os limites fazem fronteira pantaneira com Poconé/MT e Corumbá/MS e com a Bolívia, também por terra, e com os demais municípios que foram sendo emancipados de seu antigo território: Mirassol D'Oeste, Rio Branco, Salto do Céu, Jauru, Porto Esperidião, Pontes e Lacerda, São José dos Quatro Marcos, Araputanga, Reserva do Cabaçal, Figueirópolis, Porto Estrela (este localizado no antigo caminho à Barra do Bugres), Glória D'Oeste, Lambarí D'Oeste e Curvelândia (MATO GROSSO, 2008).

${ }^{5}$ Atualmente o município de Nova Olímpia tem $1.518,0 \mathrm{k}^{2}$, fazendo divisa com os municípios de Denise, Barra do Bugres, Tangará da Serra e Santo Afonso, tem uma população de 19.474 habitantes, sendo 9.907 homens e 9.567 mulheres (MATO GROSSO, 2011).
} 
No entanto, nestes dois espaços socioculturais, as dinâmicas das relações de poder no contexto da escola e a formação dos professores são bem distintas, assim como as contradições que podem auxiliar os processos de aprendizagens das crianças e jovens que neste contexto passam a se identificar e compreender sua própria historicidade.

Em duas realidades bem distintas, buscamos identificar como a escola se debruçava na compreensão dos contextos multiculturais vivenciados pelos alunos e na qual está inserida. Esta realidade mato-grossense nos é evidenciada como um problema de pesquisa desde os estudos sobre as festas de santo e a participação das crianças que estão na escola nestes contextos a partir do grupo de pesquisa que na região, institucionalizado à Universidade do Estado de Mato Grosso, desenvolvia pesquisas sobre a cultura local com o objetivo de formação de professores para uma educação intercultural ${ }^{6}$.

Com a percepção da escola como um espaço de convivência interétnica e intercultural buscamos compreender como neste espaço os saberes e fazeres da comunidade escolar, especialmente os de domínio dos alunos, a cultura da população na qual a escola se insere é tratada pedagogicamente.

Assim, nos debruçamos a identificar se a cultura popular tinha espaço na escola e de que forma ela se apresentava, ou seja, o que se desvela por traz da cortina, do visível, do invisível. Não buscamos somente uma análise superficial de que a escola trabalha pedagogicamente com as diferentes culturas, mas, além disso, o que enunciam e denunciam tais práticas.

A pesquisa revelou os sentidos das práticas culturais populares na educação escolar e as relações de poder instituído que impedem uma práxis educativa voltada à diversidade étnico-cultural neste contexto, e os espaços de formação que contribuíram para sustentar as práticas pedagógicas com êxito no currículo da Educação Infantil, Ensino Fundamental e Médio.

\section{As experiências exitosas ${ }^{7}$}

\footnotetext{
${ }^{6}$ O Grupo de Pesquisa Corpo, Educação e Cultura - COEDUC -desenvolve suas pesquisas voltadas à formação de professores na região de Cáceres, buscando promover a educação intercultural no reconhecimento da diversidade étnica da população que participa da escola, especialmente as pessoas que, naquele contexto histórico, são ameríndios e afrodescendentes, em sua grande maioria, compreendendo a escola, partir desta contextualização, como um espaço de fronteira interétnica e intercultural.

${ }^{7}$ Experiências exitosas foi um conceito formado a partir das contribuições do Professor Antonio Joaquim Severino, colaborador no processo de orientação desta pesquisa, durante intercâmbio realizado junto ao seu grupo de pesquisa no PPGE/USP, na capital paulista, em abril de 2009.
} 
Vários estudos apontam que a escola ignora a diversidade nela existente e promove uma educação monocultural que exclui e não possibilita que as crianças nela se identifiquem, principalmente as crianças de classes populares.

A cultura popular é representada por seu movimento, pelo canto, pela dança, pelas festas, pela alegria. Saberes e fazeres do corpo, negados na escola. Estes, diferente do que ocorre na vida, quando relacionamos à escola, aparentam algo totalmente desprovido de si mesmos. Ou seja, de um lado estão os saberes vistos como desprovido de poder, de valor, pois resultam de produções de um determinado grupo, portanto, considerados como um senso comum a ser negado na escola; de outro lado, esta se transveste de poder para apresentar o saber válido, as produções da humanidade sendo transmitidas sob a insígnia da ciência, da verdade inquestionável.

\begin{abstract}
A educação utilitária e instrumental das escolas seriadas acompanhou toda uma vertente dominante no pensamento ocidental e deixou que duas quebras dramáticas fossem e sigam sendo consumadas. Uma é a "cientificação" crescente do conhecimento. Outra é a desqualificação de outras culturas e, sobretudo, as culturas populares, em nome de formas únicas e pretensamente civilizadas e eruditas do saber e do viver. (BRANDÃO, 2008, p.36, grifo nosso).
\end{abstract}

É possível ler e escrever sem o corpo? Olhos, mãos, percepção, cérebro? Ou escrever com o corpo "atado"? Pode-se ler e escrever sem fruir o gosto de ser comunicar? É possível falar, ler, escrever sem o brincar com o mundo? O corpo, como totalidade é a pessoa, e a vida é nele completa, mas ao fragmentá-lo em seus saberes e fazeres descolados de sentidos fragmenta-se o ser.

A escola e o professor, a fim de possibilitar a ampliação da leitura da realidade, e nisso, ampliar o conhecimento, papel fundante da escola, devem estar mais atentos a essas significações do cotidiano, mas sem deixar de cumprir seu papel social de garantir o acesso ao saber sistematizado. À escola, compete este papel de interlocução entre diferentes saberes que ampliam a capacidade humana de transformar a realidade qualificando-a, pois é possível a escola estabelecer conexões de saberes para além de um formalismo arcaico e instrumental a que muitas vezes está condicionada.

Nossas relações com a criança parecem-nos ditadas pela natureza, estabelecidas com base em diferenças permanentes, biológicas (Merleau-Ponty poderia ter dito estruturais) - Nossa dominação parece-nos natural e necessária, pois a criança espera tudo de nós. As crianças nos parecem dadas como posse, em vista de suas 
semelhanças conosco, porque parecem continuação nossa, encarregadas pela natureza de realizar nossas esperanças. Nossa atitude parece-nos justificada e até imposta pela "natureza", pois esta traz ao mundo a criança em estado de desnudamento e impotência. (MERLEAU-PONTY, 2006, p.86).

A partir desta visão que não reconhece a criança como um ser igual ao adulto, os professores no âmbito educacional mantêm a prática de currículo fragmentado e uma formação de educadores cada vez mais distante dos sujeitos nele inseridos, corpos cada vez mais inertes nas carteiras. Vivencia-se cotidianamente a domesticação do corpo e a "morte" em vida do aluno. Como afirma Rezende (1990, p.49) a partir da fenomenologia, “[...] o homem não aprende somente com sua inteligência, mas com todo seu corpo e suas vísceras, sua sensibilidade e imaginação".

Historicamente a educação brasileira atuou de forma a fragmentar os diferentes saberes, isto é, o conhecimento sempre foi visto como algo ligado ao puro intelecto, como razão absoluta, fragmentando assim, corpo/mente, matéria/espírito, afeto/cognição. Diferente do que busca reforçar a escola,

\begin{abstract}
A mente não é uma entidade "des-situada", desencarnada ou um computador, também a mente não está em alguma parte do corpo, ela é o próprio corpo. Essa unidade implica que as tradicionais concepções representacionistas se enganam ao colocar a mente como uma entidade interior, haja vista que a estrutura mental é inseparável da estrutura do corpo. Essa compreensão da percepção é possível porque os sentidos não são considerados janelas do conhecimento. Desse modo, embora o estímulo exista como estímulo, ou seja, embora o estímulo impressione os sentidos, oferecendo informações ao organismo, ele assume configurações variadas para cada acontecimento. Assim, a percepção não apenas decodifica estímulos, linearmente, mas reflete a estrutura do nosso corpo perante o entorno, em contextos múltiplos. (NÓBREGA, 2005, p.607).
\end{abstract}

Assim, pensar as relações pedagógicas e a aprendizagem na escola a partir de outras premissas e não somente na perspectiva do intelecto ou a razão absoluta se faz necessário.

O conhecimento, nesta perspectiva:

[...] não se esgota, então, nas relações de saber, no meramente racional, mas implica o sensível, o afetivo, o emotivo, o operacional, o volitivo; implica o poder e o prazer. O conhecimento é relação, criação de vínculos, muito mais do que construção de representações teóricas da realidade. O processo de produção do conhecimento é constituído pelo conjunto de relações que se estabelece - com as 
pessoas, com a vida, com a natureza, com as situações, com a história, com os autores [...]. (AZIBEIRO, 2002, p.71).

Constatamos que as crianças, em Cáceres, que participam das manifestações populares são as mesmas que estão na escola, mas são diferentes corporalmente nestes contextos educativos. Observamos que aquela curiosidade do menino e da menina diante do palhaço na Folia de Reis, diante do Altar nas rezas, ou na Dança do Siriri, não se verifica na escola. Nesta, a disciplina do corpo é tão intensa que se percebe, mesmo não podendo generalizar a todas as salas de aulas visitadas na pesquisa, que nas crianças do contexto escolar, já não mais há aquele olhar atento, aquele corpo que se expressa, aquele ser vivaz diante do processo de conhecimento da vida.

O sentido dos acontecimentos está no corpo. "Não há mais essências acima de nós, objetos positivos, oferecidos a um olho espiritual, há, porém, uma essência sob nós, nervura comum do significante e do significado, aderência e reversibilidade de um a outro, como as coisas visíveis são as dobras secretas de nossa carne e de nosso corpo". (MERLEAU-PONTY, 1992 apud NÓBREGA, 2005, p.606).

Com isso, percebemos a relevância de refletirmos sobre a formação de professores, pois, se não há uma formação desses sujeitos que supere a visão etnocêntrica e monocultural da educação, certamente não haverá mudanças significativas que permitam ao professor ter autonomia para pensar sobre sua práxis para além do ensino técnico, mas olhar a diversidade étnico-cultural como uma possibilidade de efetivar uma educação menos excludente e mais humana. Para Libâneo (2006, p.44):

A cultura escolar inclui também a dimensão afetiva. A aprendizagem
de conceitos, habilidades e valores envolve sentimentos, emoções
ligadas às relações familiares, escolares e aos outros ambientes em
que os alunos vivem. Proporcionar uma aprendizagem significativa
supõe por parte do professor conhecer e compreender motivações,
interesses, necessidades de alunos diferentes entre si, capacidade de
comunicação com o mundo do outro, sensibilidade para situar a
relação docente no contexto físico, social e cultural do aluno.

Nessa perspectiva, ao afirmar que há necessidade de efetivar práticas educativas que não estejam fragmentadas da realidade do educando, devemos nos preocupar também com o outro extremo dessa realidade educacional, isto é, os educadores e a 
formação desses profissionais no que se refere à atenção para a diversidade étnicocultural, para uma educação intercultural. Para Fleuri (2001, p.142),

[...] a perspectiva intercultural de educação, enfim, implica mudanças profundas na prática educativa, de modo particular na escola. Pela necessidade de oferecer oportunidades educativas a todos [...]. Pela necessidade de desenvolver processos educativos, metodologias e instrumentos pedagógicos que deem conta da complexidade das relações humanas entre indivíduos e culturas diferentes. E pela necessidade de reinventar o papel e o processo da formação de professores.

Quando voltamos nosso olhar para a prática do educador, necessariamente buscamos captar até que ponto o trabalho com a cultura possibilita na educação formal uma educação que não se restringe a somente ficar no senso comum, mas atende naquilo que é a função da escola, lidar com o saberes sistematizados. Como afirma Gomes (2008, p.33) “[...] não se trata de negar a importância do conhecimento escolar, mas de abolir o equivoco histórico da escola e da educação de ter como foco prioritariamente os "conteúdos" e não os sujeitos do processo educativo".

Ao questionar os objetivos e conteúdos trabalhados pelas educadoras nesta pesquisa observamos que a maioria tem a noção clara que ao trabalhar com a cultura não deve perder de vista o foco principal, isto é, quais as possibilidades de se trabalhar, a partir do recorte da cultura, com os conteúdos escolares.

Buscamos saber das educadoras, quais objetivos sustentam suas práticas quando trabalham com a cultura em sala de aula. Quando voltamos nosso olhar para as práticas dos educadores, percebemos um movimento permanente da busca dessa articulação e do não esvaziamento de conteúdos, como suas maiores preocupações pedagógicas. Outra preocupação na efetivação dessas práticas tem sido a valorização das identidades da diferentes culturas em relação.

O objetivo é primeiramente incentivar a leitura né, porque pra eles conhecerem primeiro eles têm que buscar a leitura, tem que procurar buscar acervos que retratam esses assuntos, a melhoria da escrita, da leitura e também pra eles estarem valorizando a questão da cultura deles, uma coisa nossa, conhecer e também despertar neles essa questão da criatividade artística, porque a nossa cultura ela é muito rica [...]. (E.S.L./MT/Cáceres/ segundo ano).

Valorizar as expressões folclóricas, como forma de preservação do conhecimento popular, as lendas e resgate da 
identidade cultural do nosso município. (M.G.A./SP/Cáceres/primeira fase do primeiro ciclo).

$\mathrm{Na}$ entrevista com a professora (E.B.S.S./MT/Cáceres/3 ${ }^{\mathrm{a}}$ série do ensino fundamental), podemos analisar como uma prática pode ter múltiplos sentidos na sua ação, e principalmente sua fala nos revela como a escola olha com mais desconfianças do que confianças nos saberes populares ao enfatizarmos isso adentraram no campo da formação dos educadores.

[...] o objetivo maior era levar e mostrar que através de práticas pedagógicas pode-se trabalhar a cultura, relacionar com os conteúdos da escola, a prática informal com a formal dentro da escola que eu percebi que a escola não considera que o trabalho com a cultura na escola vá trazer resultados pra essas crianças; que essa criança vai ter compreensão de conteúdos, e eu pude trabalhar: trabalhei português, trabalhamos matemática, trabalhamos história e ciências naturais, tudo relacionado, referente à cultura tradicional mato-grossense. (E.B.S.S./MT/Cáceres/3ª série do EF).

Outro questionamento às professoras foi a respeito de como implementaram as aulas com o trabalho com a cultura popular. Explicitaram que as aulas exigiram delas um aprofundamento maior sobre as realidades locais e exemplificam como estas foram pensadas e executadas metodologicamente:

A princípio eu tentei instigar os alunos, para saber o que eles conheciam e sabiam sobre o tema, sobre a questão das manifestações culturais locais, poucos sabiam, mas os que sabiam, ficaram um pouco resistentes ou tímidos ao dizer; ao se expressar, depois desse primeiro resgate do conhecimento prévio, levei a questão da importância de discutir isso em sala de aula, da importância da cultura e a leitura dos textos, a leitura dos textos e a discussão dos grupos, depois grupos menores e o debate ou plenária, onde os grupos apresentaram as leituras ou a interpretação das leituras. E algumas questões de interpretação para ser um pouco direcionada a leitura e debates com perguntas deles e minha também, eu perguntava sobre o texto, algumas coisas sobre o texto eles respondiam e também lançaram algumas perguntas para que eu pudesse responder as dúvidas que eles ainda tinham sobre o texto [...]. (E.R.S.C./MT/Cáceres/3a ano - EM).

[...] eu expus pra eles leituras, pequenas leituras referentes ao tema, peguei um material bibliográfico do projeto COEDUC do livro Cultura e Dança e fui contando pequenos trechos da cultura, o que falava do Siriri, o que falava do Cururu, que falava da viola de cocho, das Festas de Santos, fiz aquela uma aula expositiva pra eles e assim em vários momentos era interrompida [...] eu ouvia a fala deles. 
Posteriormente a gente passou pra parte escrita pra gente registra tudo aquilo que nós falamos e discutimos [...] produzimos textos coletivos [...] no final todos assinavam lá na lousa o nome deles, porque todos eram autores daquele texto e ai posteriormente eles faziam o registro no caderno, levei pra sala de aula os instrumentos para que eles fizessem o manuseio, um ensinando pro outro [...]. (E.B.S.S./MT/Cáceres/ $3^{\mathrm{a}}$ série do EF).

Observamos então, que a metodologia empregada pelas educadoras a fim de garantir os objetivos revelam múltiplos sentidos, alguns de forma mais didática a fim de garantir os conteúdos ministrados, outros buscam superar as técnicas corriqueiras, mas em cada turma fazem o trabalho pedagógico de acordo com o nível de ensino. A didática aplicada nos remete a afirmação de Gadotti (2008, p.109): “[...] para ser emancipatória a educação precisa considerar as pessoas, suas culturas, respeitar o modo de vida das pessoas, sua identidade". Ou seja, elas inseriram autoridades culturais da comunidade no trabalho pedagógico, aproximando a comunidade da escola, e buscando no mundo vivido, nas experiências culturais vividas pelos alunos em sua comunidade, saberes e práticas para desenvolver a prática pedagógica.

Constatamos que esse trabalho não é fácil, ele implica em reconhecimento das diferenças, e o conhecimento das manifestações populares, e, principalmente em saberes e práticas que permitam as educadoras à realização de aulas que não sejam dissociadas ou esvaziadas de conteúdo, ao mesmo tempo em que esses conteúdos precisam vir regados de outra concepção de educação, aquela que reconhece os alunos como sujeitos históricos. Isso vai ficar evidente quando observamos os resultados dos trabalhos realizados, conforme as vozes das educadoras quando questionadas sobre os resultados das práticas:

Eu acho muito importante, muito significativo, tenho certeza que os alunos que passaram por mim neste terceiro ano, levaram muita coisa interessante [...] aprendizado; a maioria se envolveu com o trabalho, manifestou interesse de estar desenvolvendo algo maior na escola. Teve três ou quatro alunos que veio me procurar depois para estar desenvolvendo o trabalho de dança, de canto na escola. [...] vejo que precisa ser desenvolvido mais isso na escola, porque talvez a falta de interesse seja por falta de conhecimento, falta de contato com essas manifestações culturais. (E.R.S.C./MT/Cáceres/3 ano- $\mathrm{EM})$.

[...] quando eu cheguei à sala eu percebi que eles não gostavam dessa parte que era fazer a produção de texto [...]. Era a atividade que eles não gostavam de fazer, porém através dos conteúdos relacionados à cultura eles faziam tranquilamente, bem 
como as produções de cartazes. (E.B.S.S./MT/Cáceres/3a série do $\mathrm{EF})$.

Nas narrativas acima, evidenciamos que o processo pedagógico requer persistência e principalmente novas formas de conceber o conhecimento. Observamos também que em todos os relatos, as professoras evidenciam uma aprendizagem escolar que diz respeito às competências e habilidades nas diversas disciplinas e que seus resultados possibilitem uma educação que versa sobre as culturas, dos quais muitos alunos são produtores, uma educação que permite a proximidade da família e da comunidade na produção do conhecimento escolar.

Em Nova Olímpia-MT, o trabalho proporcionou a compreensão da diversidade cultural e do reconhecimento de pertença a um determinado grupo social, contribuindo para minimizar as relações preconceituosas existentes naquela realidade social: “ $A h$, para mim foi maravilhoso, foi verdadeiramente um projeto de cultura, ali eu aprendi muito e quebrei preconceitos, porque eu era preconceituosa [...]" (S.N.A.A./Aluna/2 ano E.M/Nova Olímpia). E referindo-se aos impactos do projeto desenvolvido pela professora a mesma aluna afirma:

Nossa, eu gostei demais! E quando tiver outro eu quero participar de novo porque foi muito bom [...] a gente fica mais [...], a gente sente prazer em ir à escola. Porque você chega lá e você pega uma matéria, às vezes se ela fosse desenvolvida diferente você até sentiria mais atraído, mas como é passado ali, você copia e pronto. De repente já é passada uma prova, você não aprende nada, não fica nada, porque você decorou aqueles minutos e de repente você esquece tudo. Agora quando você faz assim, você vê o resultado! Ah não! O conhecimento fica, fica mesmo, você não esquece! (S.N.A.A./ Aluna/ $2^{\circ}$ ano ensino médio/Nova Olímpia).

Com isso, a educanda afirma que a vivência da identidade marca o corpo, quando há produção, o conhecimento marca e fica, não é memorizado, mas vivenciado com sentido e significa para a vida, num constante aprendido.

A professora (E.B.S.S./MT/Cáceres/3a série do EF), ao trabalhar as danças com a turma da segunda série, organizou a turma de forma que alguns alunos iriam dançar e alguns meninos iriam tocar os instrumentos numa reprodução social da festa, seriam eles os cururueiros. No seu relato, o que mais foi evidenciado foi o fato de um menino evangélico ter afirmado inicialmente, em sala de aula, que ele, mesmo participando de todas as atividades na sala de aula, não iria poder tocar o ganzá na apresentação, pois a 
sua religião não permitia. A professora, respeitando sua decisão observava que o garoto estava sempre tocando ganzá durante as atividades, e no dia da festa junina ele a surpreende:

Isso pra mim foi bastante gratificante quando eu cheguei ao portão da escola já estava ele a avó dele e a irmã, e já pegou o ganzázinho dele e foi lá pro pátio, todo caracterizado, e participou tranquilamente [da apresentação da turma na festa]. Terminou a apresentação eles [o aluno e a família] se retiraram do evento. Então eu vi que superou, foi além: não é dizendo que ele mudou de religião, a avó mudou de religião, foi um momento ali que ele participou dentro da sala de aula e posteriormente levou a socialização pra comunidade; o trabalho da sala com uma tranquilidade; a avó assistiu, a irmã assistiu e depois foram embora; então ele participou desse momento. (E.B.S.S./MT/Cáceres/3a série do EF).

Compreendemos o quão difícil é lidar com as diferentes identidades nesses espaços, identidades que requerem um cuidado de olhar o outro em sua especificidade; nesse sentido, é preciso apurar os sentidos, a sensibilidade de perceber essas diferenças não como desigualdade ou como um fator para homogeneizar tudo e todos, onde não é preciso abandonar a sua cultura, nem tão pouco se fechar na cultura de origem.

Respeitar a diferença não pode significar 'deixar que o outro seja como eu sou' ou 'deixar que o outro seja diferente de mim tal como eu sou diferente (do outro)', mas deixar que o outro seja como eu não sou, deixar que ele seja esse outro que não pode ser eu, que eu não posso ser, que não pode ser um (outro) eu; significa deixar que o outro seja diferente [...]. (SILVA, 2005, p.101).

Outro aspecto que levantamos nas entrevistas foi sobre quais foram os limites enfrentados ao realizar uma prática que privilegia a cultura. Nas respostas das professoras e novamente encontramos diferentes enfoques compreendidos por ela. Dois elementos limitadores ou que contribuem para superação das dificuldades foram apontados por elas: a formação/currículo e a articulação dos conteúdos.

[...] a dificuldade mesmo foi a fonte de pesquisa mesmo, material pra trabalhar. (S.M.C./MT/Cáceres/primeiro ano EF).

O que senti mais dificuldade foi em conhecer também. Porque até então eu não tinha pesquisado muito sobre esse assunto, e partir de quando eu pensei em desenvolver esse trabalho, eu procurei textos, leituras, informação mesmo para tentar atender as necessidades deles, as curiosidades deles, e o que eu vejo assim, que a gente não 
tem muita formação nesse sentido nas escolas, precisaria demais formação em relação à cultura [...]. Senti mais necessidade de conhecimento em relação às práticas culturais locais! (E.R.S.C./MT/Cáceres $/ 3^{\circ}$ ano - EM).

Outro aspecto a ressaltar neste processo é a forma como vão articulando os conteúdos, uma das preocupações evidenciadas por outros educadores que observam o processo, principalmente na escola São Luiz. Esta preocupação permeia a visão das coordenações pedagógicas das escolas:

[...] a dificuldade da gente enquanto professor na sala de aula realmente colocar em prática qualquer projeto. É você encontrar dentro da sua disciplina o quê trabalhar, como trabalhar, essa é a dificuldade [...] (V.S./MT, CP).

[...] a dificuldade maior é o conhecimento mesmo, a falta mesmo também de espaço no nosso plano de trabalho, porque a gente fica tão envolvido com outras questões como a disciplina de português, matemática assim, de cumprir a grade curricular, de cumprir a matriz curricular que acaba que não deixa espaço pra essas aulas, então a maior dificuldade é essa. Então agora quando nós vamos re-planejar, refazer o nosso Projeto Político Pedagógico, aí nós vamos colocar que ele tenha a questão da cultura, porque a cultura mato-grossense é tão rica né! [...]. (M.V.P./PR/ CP).

Nas escolas que pesquisamos, no entanto, observamos que os professores, em sua maioria, utilizavam como referenciais e as produções publicadas pelo Grupo de Pesquisa COEDUC: livros publicados sobre a cultura local e também sobre práticas pedagógicas interculturais a partir da pesquisa e sua articulação com a educação das crianças, cujos conteúdos são danças, jogos e brincadeiras, festas de santos, rezas e outros saberes populares. Esta produção está disponível em sítio do Grupo na Universidade e como publicação com apoio da Fundação de Pesquisa, foi distribuída às escolas onde realizamos a pesquisa.

Neste trabalho com os saberes e experiências dos educadores, compreendemos que o problema evidenciado com o não saber articular diferentes saberes na escola, revela outros que estão por traz dele: os limites da formação e da produção de materiais didáticos para uma educação que se opõe à educação conservadora e autoritária.

[...] construção de uma escola democrática implica em repensar as estruturas e o funcionamento dos sistemas de ensino como um todo, como, por exemplo, reorganizar o coletivo dos(as) 
professores(as), criar tempos mais democráticos de formação docente e dos alunos, alterar a lógica e a utilização do espaço escolar [...]. (GOMES, 2008, p.40).

Ao levantarmos a questão da diversidade étnico cultural e racial no contexto escolar, as professoras percebiam alguma diferença no trabalho onde os conteúdos escolares eram realizados por meio dos conteúdos culturais em relação à outras práticas que não tinham essa relação entre saberes diferentes. Nossa questão era se percebiam diferenças entre as práticas exitosas e outras que produziram no cotidiano escolar, se estas também implicavam em uma nova forma de ensinar e aprender.

Foi diferente, e eu sinto que os alunos também sentiram essa diferença. [...] eles colocaram que foi positivo esse ato de trazer os instrumentos, os materiais relativos às festas tradicionais. Eu senti que no último dia eles estavam muito motivados pelo tema e isso chamou a atenção deles, porque até então eles não tinham tido esse contato na escola, talvez em casa na família, mas na escola não, então foi bem produtivo. Até [a aula] foi em forma de seminário [...] com slides, eles trouxeram também fotografias de monumentos históricos da cidade de Cáceres, artesanatos produzidos por artistas locais, foram no museu pesquisar sobre..., então assim tudo isso foi mobilização para conhecer, se não tivesse um interesse [...] seria apenas mais um seminário e não um aprendizado realmente. (E.R.S.C./MT/Cáceres $/ 3^{\circ}$ ano EM).

[...] acredito que se eu não tivesse inserido esse conteúdo da cultura tradicional mato-grossense nesse período da regência ${ }^{8}$, provavelmente eu teria desistido [de ser professora], porque eu já não conseguia nem me ouvir dentro da sala e a partir do momento que, eles começaram a trabalhar em grupo desenhando, pintando, escrevendo sobre o que eles conheciam do conhecimento que eles traziam de casa; relatos de experiências de vivências das danças, dos mais velhos passavam pra eles e o ato da dança mesmo, que pra eles era o ponto culminante da aula [...]. (E.B.S.S./MT/Cáceres/3a série do $\mathrm{EF})$.

Ao lidar com cultura no espaço escolar, tomada não mais como algo exótico e para além das datas comemorativas, a escola passa a estabelecer com seus pares, com a comunidade, com a família, com os alunos, uma relação de trocas, de respeito, de

\footnotetext{
${ }^{8}$ Esta professora se remete ao período em que fazia o Estágio como acadêmica do curso de Pedagogia na Universidade do Estado de Mato Grosso, e como bolsista de iniciação científica vinculava-se ao Grupo de Pesquisa COEDUC, e desenvolveu seus estudos sobre a educação intercultural na escola permeada pelo conteúdo das danças tradicionais e as relações étnico-raciais na escola. Com isso, é uma das professoras que também participou de cursos de formação continuada oferecidos pelo COEDUC e contribuiu com produções acadêmicas que contribuem para práticas exitosas no contexto da escola.
} 
reconhecimentos dos diferentes saberes, atiçados pela percepção e valorização das diferentes culturas em relação.

\section{Os novos sentidos da práxis na escola}

Os dados empíricos nos mostraram que a maioria das educadoras ressaltou o quanto suas práticas pedagógicas com base na cultura proporcionaram resultados positivos na educação escolar das crianças e jovens. Como estas foram capazes de produzir uma educação que não ignora os saberes escolares, mas busca na articulação e no diálogo permanente entre os diferentes saberes, oportunizar momentos de aprendizagem com sentidos e significados para a vida.

Para realização de experiências que sejam exitosas, exige-se do professor, uma constante reflexão sobre a prática e um constate diálogo com seus pares e com os educandos. Uma prática em que há cronogramas, conteúdos e objetivos bem definidos, e há também espaço para a própria discussão e construção de um conhecimento vivo e encarnado de significados, para a troca de saberes e compreensão ampliada dos conflitos cotidianos que nos criam possibilidades novas de aprender e dar sentidos à vida coletiva.

Ao abordar sobre a emergência de uma educação que privilegie a diversidade existente, se faz necessário pensar nos cursos de formação de professores que sejam capazes de formar outra sensibilidade, a da compreensão da pessoa como corpo, a fim de compreender que a produção de conhecimentos e aprendizagens escolares, deve ser pautada nos contextos da vida na qual a escola se insere, reconhecendo assim os contextos socioculturais históricos nos quais os alunos e seus familiares, que compõem a comunidade escolar, se forjam corporalmente.

No entanto, compreendemos com a pesquisa que sem uma formação adequada, o educador não consegue transpor as barreiras que o sistema escolar, o currículo, o tempo, e o desconhecimento lhe impõem, diante de uma realidade multifacetada, inacabada, complexa e dialética. Com isso, concluímos que cabe às instituições formadoras, a exemplo do que vimos com as contribuições da pesquisa e extensão de uma instituição, como novas educadoras se constituem como exitosas e significativas na vida das crianças e jovens que encontram na escola o espaço de valorização de suas identidades e de compreensão da relevância do conhecimento que possibilita ler livros e a vida. 


\section{EDUCATION AND DIVERSITY: THE SUCCESSFUL EXPERIENCES WHICH ACKNOWLEDGE THE WISDOMS AND WORKS OF CULTURE IN SCHOOL}

ABSTRACT: We researched the popular cultures in interface with school education, in order to understand the power relationships imbued on educational practices that hold back a praxis aimed to the acknowledgement of ethnical-cultural diversity. We delimitated successful experiences in two cities whose population constitution turns out from conflicting colonization processes in Mato Grosso. Ruled in previous researches which we identified the other dynamics of power among generations who feed collective life with an education marked on the knowing, praying, dancing, eating and playing body in saints' parties. We concluded that the teacher cannot transpose the school system barriers before an unfinished, complex, dialectic reality, without am education ruled on comprehension of diversified social reality and of collective learning.

KEY WORDS: Teachers' formation. Popular cultures. Successful experiences.

\section{REFERÊNCIAS}

AZIBEIRO, N. E. Relações de saber, poder a prazer: educação popular e formação de educadores. Florianópolis: CEPEC, 2002.

BRANDÃO, C. R. Viver de criar cultura, cultura popular, arte e educação. In: SILVA, R. M. C. (Org.). Cultura popular e educação: salto para o futuro. Brasília: Salto para o Futuro/TV Escola/Seed/MEC, 2008. p.25-38.

FLEURI, R. M. Desafios à educação intercultural no Brasil. In: FLEURI, R. M. (Org). Intercultura e movimentos sociais. Florianópolis: Mover, NUP, 2001. p.129-150.

GADOTTI, M. Boniteza de um sonho: ensinar e aprender com sentido: São Paulo: Editora e Livraria Instituto Paulo Freire, 2008.

GOMES, N. L. Indagações sobre currículo: diversidade e currículo. Brasília: MEC/SEB, 2008.

LIBÂNEO, J. C. Adeus professor, adeus professora? Novas exigências educacionais e profissão docente. 9.ed. São Paulo: Cortez, 2006.

MATO GROSSO (Estado). Cáceres - Governo Municipal. Cáceres: Prefeitura de Cáceres, 2008. Disponível em: <http://www.camaracaceres.mt.gov.br>. Acesso em: 09 dez. 2015.

Nova Olímpia - Institucional. Nova Olímpia: Prefeitura Municipal de Nova Olímpia, 2011. Disponível em: <http://www.novaolimpia.mt.gov.br>. Acesso em: 09 dez. 2015.

MERLEAU-PONTY, M. Psicologia e pedagogia da criança. Tradução de I. C. Benedetti. São Paulo: Martins Fontes, 2006. 
NÓBREGA, T. P. Qual o lugar do corpo na educação? Notas sobre conhecimento, processos cognitivos e currículo. Educação e Sociedade, Campinas, v.26, n.91, p.599615, mai./ago. 2005.

REZENDE, A. M. Concepção fenomenológica da educação. São Paulo: Autores Associados, 1990.

SILVA, T. T. Identidade e diferença: a perspectiva dos estudos culturais. Petrópolis: Vozes, 2005. 